\title{
Human influence on the record-breaking cold event in January of 2016 in Eastern China
}

Book or Report Section

Published Version

Qian, C., Wang, J., Dong, H., Yin, H., Burke, C., Ciavarella, A., Dong, B., Freychet, N., Lott, F. C. and Tett, S. F. B. (2018) Human influence on the record-breaking cold event in January of 2016 in Eastern China. In: Herring, S. C., Christidis, N., Hoell, A., Kossin, J. P., Schreck III, C. J. and Stott, P. A. (eds.) Explaining Extreme Events of 2016 from a Climate Perspective. American Meteorological Society, s118-s122. doi: https://doi.org/10.1175/BAMS-D-17-0095.1 (Special supplement to the Bulletin of the American Meteorological Society Vol. 99, No. 1, January 2018) Available at https://centaur.reading.ac.uk/74919/

It is advisable to refer to the publisher's version if you intend to cite from the work. See Guidance on citing.

Published version at: https://www.ametsoc.org/ams/index.cfm/publications/bulletin-of-the-american-meteorologicalsociety-bams/explaining-extreme-events-from-a-climate-perspective/

To link to this article DOI: http://dx.doi.org/10.1175/BAMS-D-17-0095.1

Publisher: American Meteorological Society 
copyright holders. Terms and conditions for use of this material are defined in the End User Agreement.

\section{www.reading.ac.uk/centaur}

\section{CentAUR}

Central Archive at the University of Reading

Reading's research outputs online 


\title{
23. HUMAN INFLUENCE ON THE RECORD-BREAKING COLD EVENT IN JANUARY OF 2016 IN EASTERN CHINA
}

\author{
Cheng Qian, Jun Wang, Siyan Dong, Hong Yin, Claire Burke, \\ Andrew Ciavarella, Buwen Dong, Nicolas Freychet, \\ Fraser C. Lott, and Simon F. B. Tett
}

\begin{abstract}
Anthropogenic influences are estimated to have reduced the likelihood of an extreme cold event in midwinter with the intensity equal to or stronger than the record of 2016

in eastern China by about two-thirds.
\end{abstract}

Introduction. A strong cold surge occurred during 21-25 January 2016 affecting most areas of China, especially eastern China (Fig. 23.1a). Daily mean temperatures dropped by up to $10^{\circ} \mathrm{C}-18^{\circ} \mathrm{C}$ within this event at individual stations in this region (CMA 2017) and broke daily minimum temperature $\left(\mathrm{T}_{\min }\right)$ records at many stations (Fig. 23.1b). The area averaged anomaly of $\mathrm{T}_{\min }$ over the region $\left(20^{\circ}-44^{\circ} \mathrm{N}\right.$, $\left.100^{\circ}-124^{\circ} \mathrm{E}\right)$ for this pentad was $-4^{\circ} \mathrm{C}(-2.2$ standard deviations) relative to the 1961-90 normal. This was the lowest temperature recorded, for 21-25 January, since modern meteorological observations started in 1960 (Fig. 23.1c). According to press reports (CMA 2017), 1.18 billion people were in the area where daily mean temperatures fell by more than $6^{\circ} \mathrm{C}$ within this event. On 24 January, the snowline even reached Guangzhou and the Pearl River Delta in southern China. This was the lowest latitude recorded since 1951. A sharp temperature drop, low temperatures, and associated freezing rain and snow caused widespread disruptions to transport, power supply, and public services, and damage to agriculture

AFFILIATIONS: QIAN-CAS Key Laboratory of Regional Climate-Environment for Temperate East Asia, Institute of Atmospheric Physics, Chinese Academy of Sciences and University of Chinese Academy of Science, Beijing, China; WANG-CAS Key Laboratory of Regional Climate-Environment for Temperate East Asia, Institute of Atmospheric Physics, Chinese Academy of Sciences, Beijing, China; Dong, AND YIN-National Climate Center, China Meteorological Administration, Beijing, China; BURKE, Ciavarella, And LotT-Met Office Hadley Centre, Exeter, United Kingdom; Dong-National Centre for Atmospheric Science, Department of Meteorology, University of Reading, United Kingdom; FREYCHET, AND TETT-School of Geosciences, University of Edinburgh, Edinburgh, United Kingdom.

DOI:10.II75/BAMS-D-17-0095.I

A supplement to this article is available online (10.1175 /BAMS-D-17-0095.2) in southern China (http://mt.sohu.com/20160210 /n437184257.shtml; last accessed 19 March 2017).

Cold extremes have been gaining wide attention in many parts of midlatitude Eurasia and North America in recent years (e.g., Mori et al. 2014; Trenary et al. 2016; McCusker et al. 2016). It is controversial whether they are related to Arctic warming. Some studies suggested that greenhouse-gas-induced global and Arctic warming may enhance the meandering of the jet stream thus increasing the probability of cold extremes in certain regions (Francis and Vavrus 2015), and that the Arctic warming in the Barents-Kara Seas is closely connected to the cooling in eastern Asia (Kug et al. 2015) and robust Arctic sea-ice influence on recent increases in Eurasian cold winters (Mori et al. 2014). However, other studies have suggested that the Arctic warming does not cause midlatitude cooling (e.g., McCusker et al. 2016; Sun et al. 2016).

Given the impact of this cold event in China and the controversy whether Asian midlatitude cold surges are becoming more likely as a consequence of Arctic warming, it is compelling to investigate how much anthropogenic forcing agents have affected the probability of cold events with an intensity equal to or larger than the January 2016 extreme event. We use the Met Office Hadley Centre system for attribution of extreme weather and climate events (ACE; Christidis et al. 2013; Burke and Stott 2017) and station observations to investigate the effect of anthropogenic forcings on the likelihood of such a cold event.

Data. We used observational data for $\mathrm{T}_{\min }$ from 744 national Reference Climatic and Basic Meteorological Stations from the China National Meteorological Information Centre for the period 1960-2016. From 1960 to 2013, the updated temperature dataset 

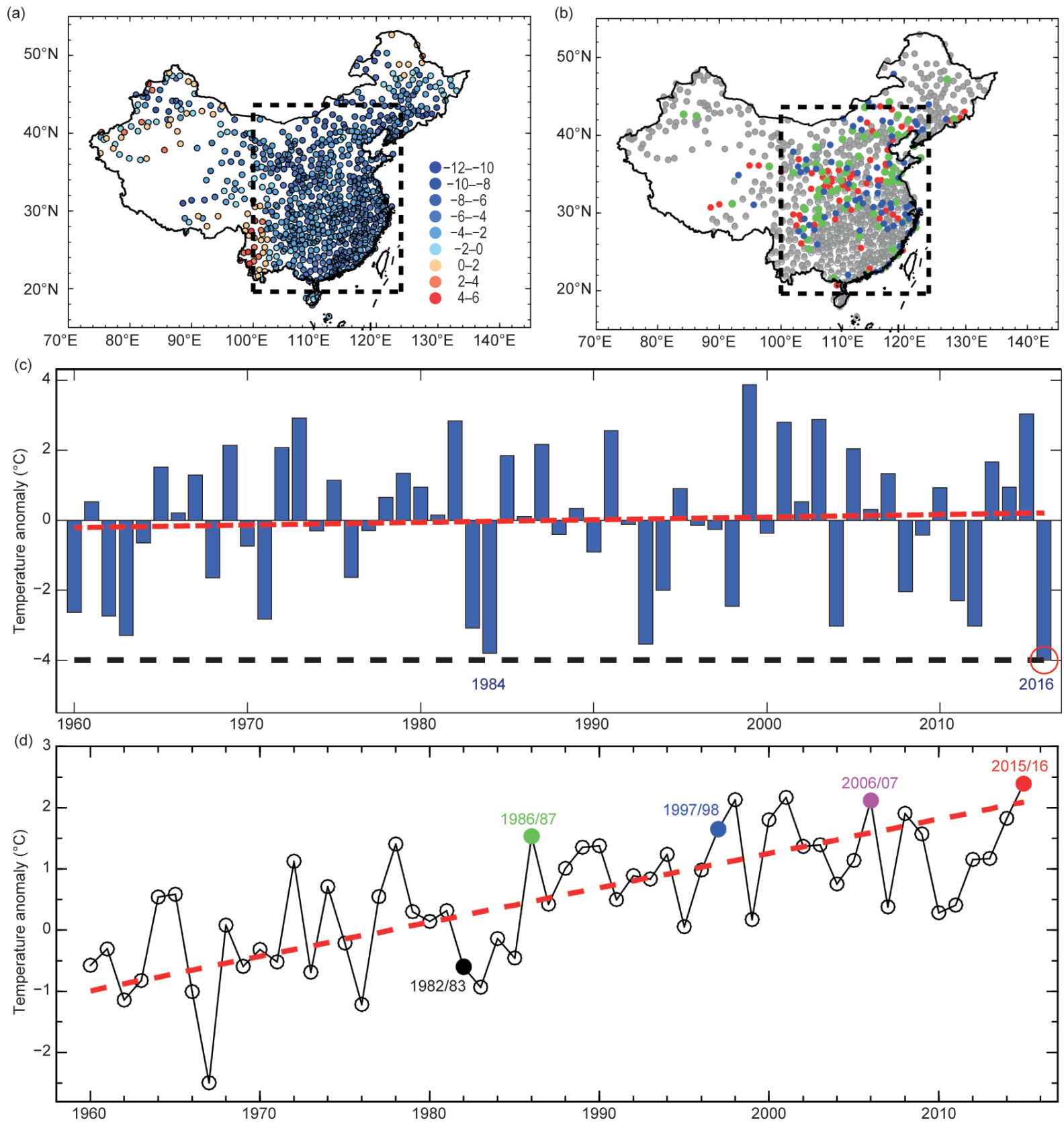

Fig. 23.I. (a) Observed pentad $T_{\min }$ anomalies ( ${ }^{\circ} \mathrm{C}$; relative to $196 \mathrm{I}-90$ climatology) for $2 \mathrm{I}-25 \mathrm{Jan} 2016$. Dashed box indicates study region $\left(20^{\circ}-44^{\circ} \mathrm{N}, 100^{\circ}-124^{\circ} \mathrm{E}\right)$; (b) Colored dots represent stations that in 2016 recorded coldest (red), second coldest (green) and third coldest (blue) pentad $\mathrm{T}_{\min }$ for any 2I-25 Jan since 1960; (c) Time series of area-weighted average $21-25$ pentad $\mathrm{T}_{\min }$ anomaly ${ }^{\circ} \mathrm{C}$ over study region for 1960-2016. Red line shows linear trend of $0.078^{\circ} \mathrm{C}_{\text {decade }}^{-1}$; (d) Averaged winter $\mathrm{T}_{\min }$ anomalies ${ }^{\circ} \mathrm{C}$ and corresponding linear trend over 1960/6I-2015/16 in target region. Labeled dots show EI Niño years

developed by Li et al. (2015) is used. This dataset was homogenized using the Multiple Analysis of Series for Homogenization (MASH) method (Szentimrey 1999) and was improved in terms of physical consistency among diurnal temperature records (Li et al. 2015), such that the temperature observations were qualitycontrolled and adjusted for most nonclimatic biases due to the changes in the local observing system, such as station relocation. After 2013, it is updated directly from those stations that have continuous records to January 2016.

We used simulations of the Hadley Centre Global Environmental Model version 3 Global Atmosphere 6.0 (HadGEM3-GA6; Walters et al. 2017) at N216 
resolution. Daily outputs of $\mathrm{T}_{\min }$ at approximately $0.56^{\circ} \times 0.83^{\circ}$ horizontal resolution are used. Fifteen members of the historical (all forcing) 1961-90 period (histClim) are compared with observations to estimate the model bias. Two ensembles of 525 members with and without anthropogenic forcings are provided for January 2016 to estimate the risk of such a cold event. One of these ensembles (histALL) uses historical anthropogenic and natural forcings and is an extension of the previous 15-member histClim runs. The other ensemble (histNAT) uses natural forcings only and is a continuation of a historical natural ensemble of 15 members, complementary to the histClim runs. Beyond the initial conditions of this continuation, the only difference between each of the 525 members in these experiments is the stochastic physics seed, and they are therefore considered equivalent. The boundary conditions for the histNAT experiments (see online supplement) are the same as in previous experiments using an earlier version of Met Office attribution system (Christidis et al. 2013).

Methods. For each station, the observed daily $\mathrm{T}_{\text {min }}$ anomaly relative to 1961-90 was calculated, from which the pentad-mean $\mathrm{T}_{\min }$ anomaly for 21-25 January $\left(\mathrm{PT}_{\min }\right)$ of each year was computed. These $\mathrm{PT}_{\text {min }}$ were gridded into $2^{\circ} \times 2^{\circ}$ grid boxes for the region $\left(20^{\circ}-44^{\circ} \mathrm{N}, 100^{\circ}-124^{\circ} \mathrm{E}\right)$ by simply averaging the available station data within a $2^{\circ} \times 2^{\circ}$ grid box. This region was chosen because the $\mathrm{PT}_{\text {min }}$ had a large negative anomaly in most stations of this region (Fig. 23.1a). We also calculated the regional average winter (December-February, DJF) $\mathrm{T}_{\min }$ anomalies over the region.

To make observations and simulations comparable, the following steps were adopted: 1) For both histALL and histNAT ensembles, daily anomalies (relative to 1961-90 normal for histClim) were computed removing any constant model bias; 2) $\mathrm{PT}_{\text {min }}$ for 2016 in histALL and histNAT runs were calculated and a land-sea mask applied; 3) These masked anomalies were regridded to the same $2^{\circ} \times 2^{\circ}$ grid boxes as the observations using linear interpolation and masked by the observational gridded data; 4) Gridded observations were then masked by this simulated data; 5) The area-weighted average $\mathrm{PT}_{\text {min }}$ of both the observations (Fig. 23.1c) and the 525 histALL and histNAT runs were then computed.

To estimate the attributable risk (Stott et al. 2004, 2016) of such an extreme cold event in midwinter, area-weighted average $\mathrm{T}_{\min }$ anomalies of 9 nonoverlapping pentads from the coldest period in the climatology (1 January to 15 February) from the 525 histALL and histNAT runs were calculated and fitted to probability distribution functions (PDFs). Goodness-of-fit was tested for Gaussian and generalized extreme value (GEV) distributions. The GEV fit was found to be the most appropriate (Fig. ES23.1) and return periods of an event like the one in 2016 were estimated from this GEV fit. The shape, scale, and location parameters of the GEV fit for histALL (histNAT) runs are $-0.28,2.35$, and $-0.21(-0.31,2.25$, and -1.39 ), respectively.

Results. Figure 23.1a shows that during this extreme cold event, most stations in eastern China recorded negative $\mathrm{PT}_{\text {min }}$, with the largest negative anomalies below $-4^{\circ} \mathrm{C}$. The $\mathrm{PT}_{\text {min }}$ broke the historical low temperature records for the same pentad at more than twenty stations, and many more recorded the second and third coldest pentad since 1960 (Fig. 23.1b). The linear trend in the regional average $\mathrm{PT}_{\text {min }}\left(\mathrm{RAPT}_{\text {min }}\right.$; Fig. 23.1c) is $0.078^{\circ} \mathrm{C}$ decade $^{-1}$ with $95 \%$ confidence interval $(-0.26,0.45)$, which is not statistically significant. This trend slope and significance testing is based on the nonparametric Sen's slope and Mann-Kendall test taking into account the first-order autocorrelation estimated by an iterative method (Wang and Swail 2001; WS2001). The 2016 RAPT ${ }_{\min }$ is the coldest 21-25 January in the record, which started 1960, beating the previous record in 1984 (Fig. 23.1c). Figure 23.1d shows that this cold event occurred in a background of the warmest winter $\mathrm{T}_{\min }$ since 1960, showing a warming trend of $0.56(-0.05,1.0054){ }^{\circ} \mathrm{C}$ decade $^{-1}$ estimated also by WS2001, and that El Niño tends to be associated with warm winters (four-outof-five El Niño years since 1982).

Figure 23.2a shows an overall mean shift toward warmer anomalies in histALL relative to histNAT indicating that human influences have reduced the risk of extreme cold events. To estimate the attributable risk ratio, we defined a threshold of $-4^{\circ} \mathrm{C}$ based on the observed RAPT ${ }_{\text {min }}$ for 2016. The probability (P0) of an event equal to or colder than this threshold in midwinter in histNAT is $6.8 \%$, whereas in histALL (P1) it is only $2.3 \%$. The risk ratio $(\mathrm{P} 1 / \mathrm{P} 0)$ is approximately $34 \%$, which suggests that human influences have reduced the risk of such an extreme cold event by about $66 \%$. We estimated the uncertainty of P1/P0 by resampling the PDF 1000 times (Pall et al. 2011). Results show that P1/P0 lies between $31.1 \%$ and $37.8 \%$ (one standard deviation), suggesting that human influences reduced the probability of such a cold event by approximately two 
(a)

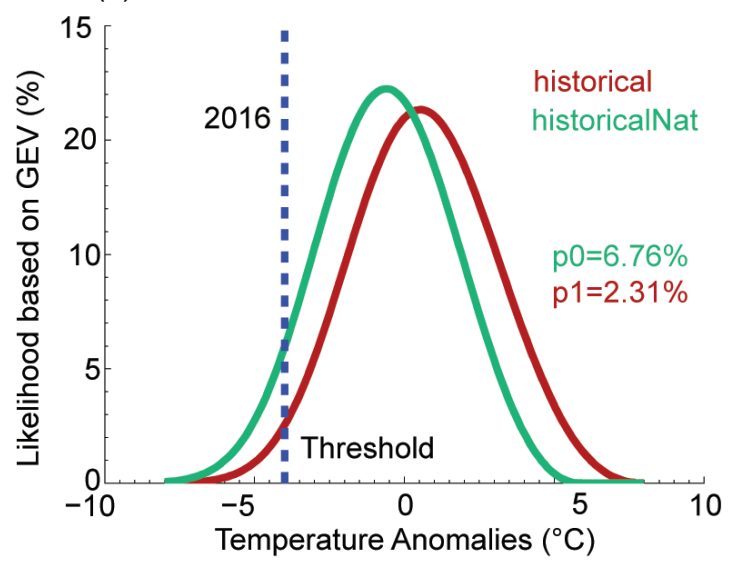

(c) (b)

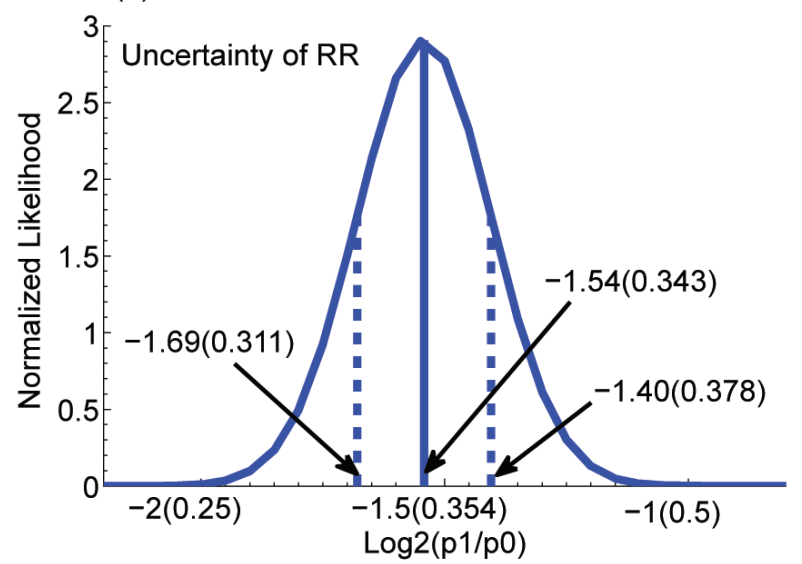

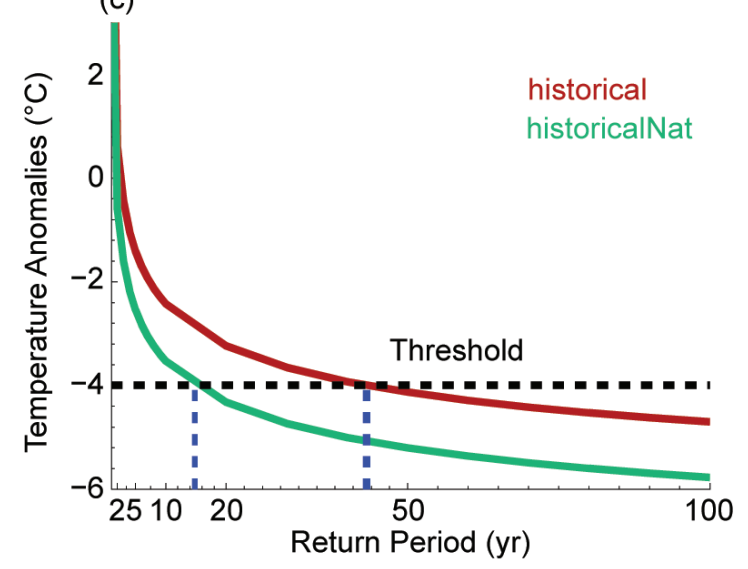

Fig. 23.2. (a) GEV distribution fit to $9 \times 525$ regional average pentad $T_{\min }$ anomalies ${ }^{\circ} \mathrm{C}$ during midwinter 2016 in eastern China from histALL simulations (red line; with anthropogenic and natural forcings) and that from histNAT simulations (green line; only with natural forcings). Dashed line indicates threshold, which is regional average pentad $T_{\min }$ anomaly of 2I-25 Jan 2016 in observations. (b) Uncertainty in attributable risk ratio of such extreme cold event due to anthropogenic influences. Dashed lines indicate one standard deviation. (c) Return period (years) of extreme cold event with intensity equal or larger than extreme cold event of Jan 2016 in eastern China in histALL (red line) and histNAT simulations (green line). Black dashed line indicates threshold used in (a).

thirds (Fig. 23.2b). The estimated return period of $\mathrm{RAPT}_{\text {min }}$ like January 2016 is one-in-15 years with only natural forcings while it is extended to one-in-43 years with anthropogenic forcings (Fig. 23.2c).

Conclusions and discussion. Cold winters in China are expected to become rarer in a warming climate. By employing high quality station observations and model simulations, we estimate that anthropogenic influences have reduced the occurrence probability of an extreme cold event with the intensity equal to or stronger than the record in 2016 by approximately two-thirds. Conversely, if there were no anthropogenic influences, the probability of an extreme cold pentad in 2016 would be more than double. The return period of such a record cold event is estimated to have been extended by about 28 years due to human influences. Our results are in line with McCusker et al. (2016) and Sun et al. (2016) and agree with Trenary et al. (2016) that despite severe cold surges and recordbreaking extreme cold-day occurrences during 2016, winters have become warmer. Our results also imply that even under human-induced warming, extreme cold events can still occur as a result of natural variability, such as Arctic Oscillation, which was believed to be responsible for the reporting event (Cheung et al. 2016).

ACKNOWLEDGMENTS. We are grateful for the comments and suggestions provided by the editor and the reviewers. This study was largely carried out during a workshop on Operational Attribution at the University of Edinburgh sponsored by the U.K.-China Research \& Innovation Partnership Fund through 
the Met Office Climate Science for Service Partnership (CSSP) China as part of the Newton Fund. CQ, JW, SD and HY were funded by the National Key R\&D Program of China (2016YFA0600400), CCSF201704, CAS International Collaboration Program (2016), the NSFC $(41675074,41675093,41301041)$, the Youth Innovation Promotion Association CAS (2016075), and the Jiangsu Collaborative Innovation Center for Climate Change.

\section{REFERENCES}

Burke, C., and P. Stott, 2017: Impact of anthropogenic climate change on the East Asian summer monsoon. J. Climate, 30, 5205-5220, doi:10.1175 /JCLI-D-16-0892.1.

Cheung, H. H. N., W. Zhou, M. Y. T. Leung, C. M. Shun, S. M. Lee, and H. W. Tong, 2016: A strong phase reversal of the Arctic Oscillation in midwinter 2015/2016: Role of the stratospheric polar vortex and tropospheric blocking. J. Geophys. Res. Atmos., 121, 13,443-13,457, doi:10.1002/2016JD025288.

Christidis, N., P. A. Stott, A. A. Scaife, A. Arribas, G. S. Jones, D. Copsey, J. R. Knight, and W. J. Tennant, 2013: A new HadGEM3-A-based system for attribution of weather- and climate-related extreme events. J. Climate, 26, 2756-2783, doi:10.1175 /JCLI-D-12-00169.1.

CMA, 2017: China Climate Bulletin 2016. China Meteorological Administration.

Francis, J. A., and S. J. Vavrus, 2015: Evidence for a wavier jet stream in response to rapid Arctic warming, Environ. Res. Lett., 10, 014005, doi:10.1088/1748 -9326/10/1/014005.

Kug, J.-S., J.-H. Jeong, Y.-S. Jang, B.-M. Kim, C. K. Folland, S.-K. Min, and S.-W. Son, 2015: Two distinct influences of Arctic warming on cold winters over North America and East Asia. Nat. Geosci., 8, 759-762, doi:10.1038/ngeo2517.

Li, Z., Z. W. Yan, and H. Y. Wu, 2015: Updated homogenized Chinese temperature series with physical consistency. Atmos. Oceanic. Sci. Lett., 8, 17-22, doi:10.3878/AOSL20140062.

McCusker, K. E., J. C. Fyfe, and M. Sigmond, 2016: Twenty-five winters of unexpected Eurasian cooling unlikely due to Arctic sea-ice loss. Nat. Geosci., 9, 838-842, doi:10.1038/ngeo2820.
Mori, M., M. Watanabe, H. Shiogama, J. Inoue, and M. Kimoto, 2014: Robust Arctic sea-ice influence on the frequent Eurasian cold winters in past decades. Nat. Geosci., 7, 869-873, doi:10.1038/NGEO2277.

Pall, P., T. Ainu, D. A. Stone, P. A. Stott, T. Nozawa, A. G. J. Hilberts, D. Lohmann, and M. R. Allen, 2011: Anthropogenic greenhouse gas contribution to flood risk in England and Wales in autumn 2000. Nature, 470, 382-386, doi:10.1038/nature09762.

Stott, P. A., D. A. Stone, and M. R. Allen, 2004: Human contribution to the European heatwave of 2003. $\mathrm{Na}$ ture, 432, 610-614, doi:10.1038/nature03089.

— weather and climate-related events. Wiley Interdisc. Rev.: Climate Change, 7, 23-41, doi:10.1002/wcc.380. Sun, L., J. Perlwitz, and M. Hoerling, 2016: What caused the recent "warm Arctic, cold continents" trend pattern in winter temperatures? Geophys. Res. Lett., 43, 5345-5352, doi:10.1002/2016GL069024.

Szentimrey, T., 1999: Multiple analyses of series for homogenization (MASH). Proc. of the Second Seminar for Homogenization of Surface Climatological Data, WMO-TD-962, Budapest, Hungary, WMO, 27-46.

Trenary, L., T. DelSole, M. K. Tippett, and B. Doty, 2016: Extreme eastern U.S. winter of 2015 not symptomatic of climate change [in "Explaining Extreme Events of 2015 from a Climate Perspective"]. Bull. Amer. Meteor. Soc., 97 (12), S31-S35, doi:10.1175/BAMS -D-16-0156.1.

Walters, D., and Coauthors, 2017: The Met Office Unified Model Global Atmosphere 6.0/6.1 and JULES Global Land 6.0/6.1 configurations. Geosci. Model Dev., 10, 1487-1520, doi:10.5194/gmd-10-1487-2017. Wang, X. L., and V. R. Swail, 2001: Changes of extreme wave heights in Northern Hemisphere oceans and related atmospheric circulation regimes. J. Climate, 14, 2204-2221, doi:10.1175/1520 -0442(2001)014<2204:COEWHI $>2.0 . C O ; 2$. 